\title{
AFTER RELIABILITY CENTERED MAINTENANCE: PREVENTIVE MAINTENANCE LIVING PROGRAM (PMLP) IMPLEMENTATION AT BRUCE POWER
}

\author{
Michael L. Harazim \\ Framatome ANP \\ Brian J. Ferguson \\ Bruce Power
}

\begin{abstract}
The PMLP is the cornerstone of the IMP. It is the control mechanism for the continuous PM task improvement and is composed of five elements: 1) process control, 2) change control, 3) worker feedback, 4) program performance metrics, and 5) a PM deferral module. Without a PMLP the PM program could not be truly integrated with station processes and would drift integrated with station processes and would drift back to an uncontrolled, inefficient and ineffective state.
\end{abstract}

Framatome ANP (formerly Duke Engineering \& Services Inc.) had previously developed and implemented a software tool to facilitate the PM Living Program management at the Duke Energy nuclear sites. The OPG PMLP Workstation was developed by using the existing Duke Energy PMLP software as a base.

The PM Living Program Workstation is now in use at the Bruce, Darlington and Pickering nuclear Sites. 